Rozprawy Komisji Językowej ŁTN, t. LXVII, 2019

ISSN 0076-0390; e-ISSN 2450-9310

https://doi.org/10.26485/RKJ/2019/67/17

Angelika Pawlaczy**

(1) https://orcid.org/0000-0002-4629-8952

\title{
SYTUACJA JĘZYKOWA MNIEJSZOŚCI POLSKIEJ W STRYJU (UKRAINA)
}

\section{THE LANGUAGE SITUATION OF THE POLISH MINORITY OF STRIY (UKRAINE)}

This article discusses the linguistic situation of the Polish minority in Striy on the basis of the three chosen linguistic biographies. The initial analysis of the data allows us to state that the Polish language of the Polish Striy community is not free of East Slavic influences. It is still considered as important in their system of values which partly stems from their origin and family traditions.

Keywords: language situation, Polish minority, Striy, bilingualism

Słowa kluczowe: sytuacja językowa, polska mniejszość, Stryj, dwujęzyczność

Ukraina Zachodnia obejmuje siedem obwodów: wołyński, rówieński, lwowski, tarnopolski, iwanofrankowski, zakarpacki i czerniowiecki [Olszański, 2013, s. 13]. Jednym z miast istniejących w Galicji Wschodniej i liczącym ponad 20 tys. mieszkańców jest Stryj. Bronisław Chlebowski i Władysław Walewski w swoim opracowaniu sprzed ponad stu lat charakteryzują miasto w następujący sposób:

Stryj, miasto powiat. w Galicyi ${ }^{1} 75 \mathrm{klm}$. na płd. ode Lwowa, [...]. Miasto leży w równinie. Płd.-wsch. część obszaru przepływa Stryj od płd.-zach. na płn.-wschód a część płn.-zach. [...] Zabudowania leżą przeważnie w płd. części obszaru, a mianowicie w dolinie Stryja, po obu bokach gościńca miasto właściwe z obszernym rynkiem, a dokoła niego przedmieścia: Łany Dolno i Górne, Podzamcze, Szumlańszczyzna, Wójtowstwo, i grupy domów: Marcynówka, Szwaby, Zapłatyn, Zwarycze, Basiówka, Brzegi i Dąbrowa [Chlebowski, Walewski, 1890, s. 429].

* Uniwersytet Mikołaja Kopernika w Toruniu, Wydział Filologiczny, Katedra Filologii Słowiańskiej, ul. Fosa Staromiejska 3, 87-100 Toruń; e-mail: a_pawlaczyk@wp.pl.

1 Pisownia zgodna $\mathrm{z}$ oryginałem. 
Większość Polaków mieszkających na Ukrainie nie posługuje się polszczyzną w życiu codziennym. Mają na to wpływ różnego rodzaju czynniki. Eugeniusz Biłonożko podaje, że:

Głównym powodem tego, że Polacy mieszkający na Ukrainie nie rozmawiają w języku ojczystym, jest charakter osadnictwa (w odróżnieniu od mniejszości niemieckiej w Polsce i polskiej mniejszości na Litwie nie zamieszkują oni zwartego obszaru) [Biłonożko, 2013, s. 104].

Według cytowanego autora podział etniczny i językowy warunkowany jest między innymi przez wyznanie i miejsce zamieszkania. Żyjąc na wsi lub w niewielkich miastach nie ma możliwości mówienia w języku polskim i w codziennej komunikacji konieczne jest posługiwanie się językiem ukraińskim, co wynika przede wszystkim z niewielkiej liczby ludności pochodzenia polskiego zamieszkującej dane terytorium [Biłonożko, 2013, s. 103-104].

Tadeusz Olszański podkreśla, że liczba osób należących do mniejszości polskiej na Ukrainie nie tylko spada, ale i jest zaniżana w statystykach. W swoim opracowaniu przywołuje on dane z 2001 roku, z których wynika, że Ukrainę Zachodnią zamieszkiwało wtedy około 40 tysięcy Polaków [Olszański, 2013, s. 7]. Autor podkreśla, że spadająca ich liczba może mieć związek z asymilacją, wymieraniem najstarszego pokolenia oraz emigracją do Polski [Olszański, 2013, s. 79].

Ważna jest również pomoc od państwa, od której zależne są losy organizacji działających na rzecz Polonii. Duże znaczenie ma powstałe we Lwowie w 1988 roku Towarzystwo Kultury Polskiej Ziemi Lwowskiej, które obecnie liczy 21 oddziałów mieszczących się w różnych częściach obwodu lwowskiego [Olszański, 2013, s. 81]. Jednym z takich miejsc jest miasto Stryj. Z myślą o mieszkającej tam mniejszości polskiej zajęto się edukacją i krzewieniem polskiej kultury. Celem stryjskiego oddziału Towarzystwa Kultury Polskiej Ziemi Lwowskiej jest nie tylko zrzeszanie mniejszości, ale i dbanie o zachowanie oraz propagowanie wśród niej polskiej kultury, historii i tradycji. Co ciekawe, w działalność placówki zaangażować się mogą również osoby niemające polskich krewnych.

Język polski funkcjonujący na terenie Kresów Wschodnich jest przedmiotem zainteresowania wielu badaczy. O polszczyźnie północno-wschodniej pisały między innymi Iryda Grek-Pabisowa i Irena Maryniakowa [1997] oraz Kwiryna Handke [1997]. Na Kresach Południowo-Wschodnich sytuacja języka polskiego badana była na przykład przez Zofię Kurzową [1983; 1993; 1997], Janusza Riegera, Iwonę Cechosz-Felczyk i Ewę Dzięgiel [2002; 2007], Annę Kostecką-Sadową [2008; 2017], Marię Zielińską [2011; 2012] i Helenę Krasowską [2015]. Natomiast sytuacja językowa wspólnoty polskiej w Stryju w warunkach bilingwizmu polsko-wschodniosłowiańskiego nie była dotąd przedmiotem szczegółowych 
badań. Wstępne obserwacje zostały zaprezentowane jedynie w opracowaniach Michała Głuszkowskiego [2007; 2013; 2014].

W niniejszym artykule materiał językowy stanowią wywiady przeprowadzone z członkami stryjskiego oddziału Towarzystwa Kultury Polskiej Ziemi Lwowskiej, tj. Polakami lub Ukraińcami polskiego pochodzenia, którzy z polszczyzną mieli do czynienia w sytuacjach codziennych w domu rodzinnym lub których znajomość języka wynika z podjętej nauki i aktywności we wspomnianej placówce. Historie mówione zarejestrowane zostały podczas prowadzonych w lipcu 2018 roku badań na temat funkcjonowania języka polskiego i lokalnych tradycji na Zachodniej Ukrainie. Z kolei podczas towarzyszących im zajęć edukacyjnych prowadzonych w ramach Letniej Szkoły Języka i Kultury Polskiej w Towarzystwie Kultury Polskiej Ziemi Lwowskiej w Stryju zebrany został dodatkowo materiał pisany. W związku z tym zasadne wydaje się wykorzystywanie metody biograficznej, która była stosowana w podobnych badaniach między innymi przez Annę Zielińską [2013], Michała Głuszkowskiego [2018, s. 43-62] i Władysława Miodunkę [2016, s. 49-87]. Za Jackiem Leońskim przyjmujemy, że:

Metoda biograficzna, metoda autobiograficzna, metoda dokumentów osobistych, metoda pamiętnikarska to określenia, które w socjologii występują zamiennie. Często używa się tych określeń na oznaczenie pewnego postępowania badawczego. [...] Można tu wskazać na trzy możliwe płaszczyzny odniesienia: 1) pewną orientację metodologiczną, 2) przedmiot analizy (biografia lub jej fragment jako temat), 3) sposób gromadzenia danych i ich analizy (materiały, źródła analizy itp.) [Leoński, 1993, s. 25].

Materiał pozyskiwany był podczas prowadzonych w języku polskim wywiadów częściowo standaryzowanych. Ze względu na specyfikę badań autorce zależało na zebraniu zarówno materiału językowego, jak i socjolingwistycznego, dlatego podczas nagrań zadawane były pytania dotyczące życia rodzinnego, historii, religii, tradycji i obyczajów, pracy, życia codziennego, szkoły itd. Zarejestrowanych zostało około trzynastu godzin rozmów z czternastoma informatorami, którzy podzieleni zostali na trzy grupy wiekowe ${ }^{2}$. W dalszej części artykułu mowa będzie o przedstawicielach młodszego, średniego i starszego pokolenia.

W niniejszym opracowaniu sytuacja językowa wspólnoty polskiej w Stryju omówiona zostanie na przykładzie trzech biografii językowych przedstawicieli poszczególnych pokoleń. Jak pisze Jakub Kościółek:

Sytuację językową jakiegoś państwa tworzą wszystkie języki, geograficzne i społeczne dialekty, jakie służą komunikacji na każdej społecznej płaszczyźnie. Na sytuację językową

2 Podział pokoleń: 18-28 lat - pokolenie młodsze (osoby urodzone po rozpadzie ZSRR), 28-64 lata - pokolenie średnie (osoby urodzone w ZSRR, aktywne zawodowo), 65 lat i starsi - pokolenie najstarsze (seniorzy, osoby nieaktywne zawodowo). 
wpływają takie czynniki, jak: wykorzystywanie języków na każdym poziomie komunikacji społecznej, rozszerzanie lub zawężanie kręgu użytkowników języka oraz występowanie socjokulturowych i politycznych wpływów na sfery językowe [Kościółek, 2012, s. 449].

Podczas charakterystyki poszczególnych biografii nacisk kładziony będzie przede wszystkim na pochodzenie, znajomość polszczyzny, sfery jej użycia i przykładowe zjawiska językowe (np. przełączanie kodu, zapożyczenia).

Przedstawiciele młodszego pokolenia przejawiają najwyższe kompetencje w zakresie znajomości języka ukraińskiego. Oprócz tego swobodnie posługują się polszczyzną w zakresie kodu rozwiniętego (według definicji Basila Bernsteina ${ }^{3}$ ), jednak ich wypowiedzi nie są wolne od wpływów wschodniosłowiańskich. Fakultatywnie używany jest również język rosyjski. Jednym z reprezentantów młodszego pokolenia jest informator M19964. Jest on dwudziestotrzyletnim studentem i na co dzień mieszka w Morszynie. Ma polskie pochodzenie ze strony matki - jego babka była Polką mieszkającą we wsi niedaleko Stryja, która wyszła za mąż za Ukraińca i w codziennej komunikacji posługiwała się językiem ukraińskim. Jednak nie ma żadnych poświadczeń w dokumentach dotyczących jej polskiego pochodzenia. W jednej z polskich wsi mieszkał prapradziad M1996 (dziadek jego babki). W jego przypadku polskie pochodzenie jest już poświadczone. Rodzice informatora nie mówią po polsku - ojciec jest Ukraińcem, a w domu rodzinnym matki mówiono po ukraińsku. Motywacją do nauki języka polskiego był wyjazd partnerki M1996 na studia do Polski. Wtedy też zaczą on interesować się krajem przodków i poszukiwać informacji na temat swojego pochodzenia. Informator nigdy nie uczęszczał na zajęcia języka polskiego, ale ma z nim kontakt od około czterech lat. Przez trzy i pół roku uczył się samodzielnie czytać i mówić, a od około pół roku z pomocą korepetytora ćwiczy gramatykę. Oprócz tego M1996 aktywnie działa w Towarzystwie Kultury Polskiej Ziemi Lwowskiej w Stryju, dzięki któremu w lutym 2018 roku otrzymał Kartę Polaka. Mężczyzna wyraża chęć posługiwania się językiem polskim w kontaktach z babcią, w rozmowach z Polakami oraz podczas odbywających się w towarzystwie uroczystości. Wiedzę o Polsce i szeroko rozumianej polskości czerpał od babki. M1996 stara się mówić poprawną polszczyzną i posługuje się nią swobodnie:

3 Kod rozwinięty rozumiany jest zgodnie z definicją Bernsteina jako system mowy, który charakteryzuje się ,ścisłym porządkiem syntaktycznym, bogactwem określeń - przymiotników i przysłówków, różnorodnością spójników, częstym użyciem skomplikowanych gramatycznie konstrukcji zdaniowych, a szczególnie zdań podrzędnie złożonych, licznymi formami bezosobowymi” [Bokszański, Piotrowski, Ziółkowski, 1977, s. 113].

${ }_{4}$ Ze względu na gwarancję anonimowości w symbolu zakodowana została płeć i rok urodzenia informatora. 
ńe znaw ${ }^{5}$ em o tym že (v) babći jest polkom bo k'edy bywem mawym tak'im xwopak'em to ona m'i barzo opov'adawa o polsce o tym že... o tym k'im ona jest jako polka že ona jest polkom opow'adawa ružne x'istor'i: vwaśńe zw'onzane z roźinom gźe jej ojćec jeźźiv do ńem'ec f č’aśe drug'ej vojny śf'atovej / byw jeńcem jeź:iv do... na tak'e vymušone prace / no vwaśńe opov'adawa tym že k'edy jedna taka sytuac'a m'i najbarźej śe zapam'entawa zapam'entaw... no ńevažne / že k'edy pšys... pšyswano bywo pšyswano jej / ńe jej a jej ojcu tak'i... / no ńe v'em l'istufka l'ist / l'ist xyba xyba benźe l'ist / z ńem'ec ot:ego pana f kturego pracovaw.

W jego wypowiedziach odnaleźć można obce wpływy, które ujawniają się na różnych poziomach języka. W zakresie fonetyki różnice nie są właściwie zauważalne. Wyjątek stanowi miękka wymowa spółgłoski č przed samogłoską

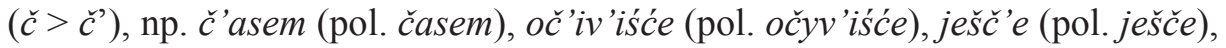
v'eč'orem (pol. v'ečorem). W analizowanym materiale językowym odnotować można liczne wstawki językowe, czyli elementy ukraińskie, które wplatane są $\mathrm{w}$ wypowiedzi nieświadomie i nieregularnie, np. to o tym jest informacija tak to jest tak zapisana (por. pol. informacja; ukr. інформація). Ciekawe są również hybrydalne konstrukcje, tworzone przez informatora spontanicznie i nieregularnie, np. momentalnie go podar... podarv podpaliv.

W przypadku pokolenia średniego konieczne było wprowadzenie rozróżnienia na pokolenie średnie młodsze i średnie starsze. Podczas prowadzonych badań udało się dotrzeć do kilku osób reprezentujących pierwszą grupę. Jednak zaledwie jedna z nich, tj. K1987, miała polskie pochodzenie. Informatorka ma 32 lata. Ma polskie pochodzenie ze strony ojca, którego matka była Polką. Z kolei matka K1987 jest Ukrainką o korzeniach rosyjskich. Informatorka podkreśla, że w dzieciństwie nie wiedziała o swoim polskim pochodzeniu, ponieważ jak wyjaśnia: „babcia wyszła za mąż za Ukraińca, no i jakby jej nie zależało na przekazaniu tej polskości dzieciom". Jednak kiedy w wieku 15 lat K1987 dowiedziała się o działalności Towarzystwa Kultury Polskiej Ziemi Lwowskiej, zaczęła interesować się swoim pochodzeniem i aktywnie działać w placówce. Od tego czasu uczy się języka polskiego i uczęszcza na nabożeństwa do kościoła:

$\mathrm{Z}$ wiarą też mam taką ciekawostkę. Zostałam ochrzczona w cerkwi prawosławnej we Lwowie. Do I Komunii Świętej przystąpiłam w cerkwi grekokatolickiej w Stryju, a teraz chodzę do kościoła i jakby kościół to taka... na pewno ta polska krew swoje dała, bo religię, wiarę przyjmuję tylko w języku polskim. Tak jakoś... tak jakoś tak krew tutaj zagrała.

5 Podczas wywiadów zaobserwowano, że $ł$ realizowane jest jako spółgłoska przedniojęzykowo-zębowa lub niezgłoskotwórcze $u$. W wymowie informatorów reprezentujących pokolenie młodsze i średnie młodsze częściej zauważa się niezgłoskotwórcze $u$, natomiast $\mathrm{u}$ informatorów reprezentujących pokolenie najstarsze - kresowe $t$. 
Mimo że wiara jest przyjmowana w języku polskim, to wielu kłopotów przysparza informatorce znalezienie odpowiedzi na pytanie dotyczące tożsamości:

To jest trudne pytanie, bo jestem z mieszanej rodziny. Posiadam Kartę Polaka, wyznaję swoją przynależność do języ... narodu polskiego. Czuję się Polką, ale nie mogę powiedzieć, że tak aż na sto procent. Bo mam... rodzina jest mieszana: ukraińska, polska i jeszcze rosyjska. $\mathrm{Na}$ tych terenach to nie wiem, co jest gorzej: rosyjska czy polska - polskie pochodzenie. Nie można tak... nie uzasadnić, ale tak powiedzieć, że... można powiedzieć, że jestem Słowianką.

Kontakt K1987 z polskim otoczeniem językowym jest ograniczony. Jednak posługuje się ona polszczyzną w zakresie kodu rozwiniętego. Oprócz tego swobodnie przechodzi z języka ukraińskiego na język polski i odwrotnie. Mimo że wypowiedzi K1987 nie są wolne od wpływów wschodniosłowiańskich (pochodzenie ukraińsko-rosyjsko-polskie), to wyróżniają się złożonością konstrukcji składniowych:

u nas ńe ma tak'ix normalnyx programuf ubesp'ečeńovyx / na pšyklat ja pracuje na państfovej fabryce i mam ubesp'ečeńe lekarsk'e čy jak ono prav'idwovo nazyva śe [...] / ub'esp'ečeńe zdrovotne pośadam jego ale co ono m'i daje / tylko ježel'i m'i ne pokladut'... pokwazom... / no na pšykwat zaxoruje tak že mam mam znajdovać śe $v$ šp'italu tylko f tak'im raźe to moje ub'esp'ečeńe pokryva lečeńe / ježel'i na pšykwat jestem xora na ... / ježel'i ja na pšykwat zaxorovawa no na pšykwat na gžype... na grype / i no i leče śe v domu to ftedy fšystk'e lek'i ja kupuje za sfoje p'eńonze / xyba to že m'i f pracy te dńi kture ja jestem xora to opwacajom.

W materiale językowym odnotować można między innymi ukraińskie wstawki, np. ne pokladut' (pol. nie położa, ukr. не покладуть), kalki gramatyczne, np. składniowe: ja pracuje na państfovej fabryce, gdzie przyimek $w$ zastapiony został przez na, co uznać można za wynik oddziaływania języka ukraińskiego, a dokładniej ukraińskiego przyimka на (por.: pol. Ja pracuję w państwowej fabryce; ukr. Я праџюю на державній фабрииі), сzy zjawisko uzupełniania kodu, np. zaxorovawa no na p̌̌yklat na gžype... na grype.

Materiał pozyskany od informatorów reprezentujących starsze pokolenie jest ważny $z$ dwóch powodów. Po pierwsze - jego przedstawiciele są cennym źródłem informacji na tematy związane między innymi z historią Polaków na Wschodzie. Po drugie - mogą być oni nosicielami południowokresowej polszczyzny. Największe zainteresowanie prowadzonymi badaniami wykazała K1942, która chętnie dzieliła się swoją wiedzą na temat historii i kultury Polaków na Ukrainie, historii rodziny czy obecnej sytuacji w kraju. Informatorka ma 77 lat i mieszka na obrzeżach Stryja. Jest wdową. Jej dziadkowie pochodzili z Krosna. W 1945 roku cała rodzina ze strony matki wyjechała do Polski. Matka wraz z mężem i dziećmi pozostała w Stryju. W domu rodzinnym mówiono po ukraińsku i po polsku. Obecnie K1942 z polszczyzną ma do czynienia w życiu codzien- 
nym, ponieważ stara się słuchać polskiego radia i oglądać telewizję oraz czytać polskojęzyczne gazety i książki. Oprócz tego informatorka regularnie chodzi do kościoła, w którym nabożeństwa prowadzone są w języku polskim. Mimo że jej naturalnym - podstawowym kodem jest język ukraiński, K1942 posługuje się swobodnie polszczyzną w zakresie kodu rozwiniętego. Wypowiedzi wyróżniają się bogactwem słownictwa i złożonością konstrukcji, co potwierdza fragment:

[...] a f čterźeśći p'ontym roku fšystka roźina mamyna to bylo to to akc'ija v'isla šo pol'acy fr̃yscy vyjež:al'i a ukraińcy s tej strony polsk'i vyjež:al'i to tu na našom strone / to mamyny tšy śostry s calomy roźinam'i vyjexal'i / a mama teš g'źeś to muj monš to roskazaw bo ja ńe ne pam'entam / mama mńe ńe ńe... šo xćela xćela teš ze mnom pojexać a zostal... / tata i ješče dva brata / jeden maw šesnaśće lat a druyi tšynaśće ońi ńe xćel'i jexać / to bylo f tym roku i mama čeres dva dńa pšyšla s_stac'iji i vrućila bo jak mala zostav'ić ix / j́eći menža i fśo / a t'i vyjexal'i / potym zafše byl'i p'iś... p'isma p'isal'i bo to babća ješče žyla / babća vyjexala ješo v:ojne /f čterǵeśći tšećim čy čfartym ńe pam'e... ńe znaju f katorym roku / z vnučkom pojexala do polsk'i do brata / krosno / bo to moja... j́adek z bapćom poxoźil'i s krosna / i ońi fr̃ystk'e vyjexal'i a mama zostala tutaj.

Z polszczyzną K1942 miała do czynienia w sytuacjach codziennych. Zarówno ten fakt, jak i wstępna analiza jej wypowiedzi sugerują że informatorka może być nosicielką południowokresowej polszczyzny. Wskazuje na to między innymi wymowa przedniojęzykowo-zębowego (kresowego) $t^{6}$, którą zdecydowanie trudniej było zaobserwować u M1996 czy K1987. Na podstawie przytoczonego wyżej fragmentu wywiadu zauważyć można, że polszczyzna K1942 nie jest wolna od wpływów ukraińskiej fonetyki czy morfologii, np. druyi (pol. drugi, ukr. друzuй), maw (pol. miał, ukr. мав), staciji (pol. stacji, ukr. станиï), šo (pol. że, ukr. щ̧о). Biorąc pod uwagę to, że w rodzinnym domu informatorki mówiono w językach polskim i ukraińskim, a oprócz tego komunikowano się również w rosyjskim nie dziwi, że podczas udzielanych wywiadów często nieświadomie przełączała ona kod, tj. swobodnie przechodziła z jednego języka na drugi, np. f čterjéść $i$ tšećim čy čfartym ńe pam'e... ńe znaju f katorym roku. Ciekawy jest również fragment: tata i ješč dva brata, w którym mamy prawdopodobnie do czynienia z wpływem wschodniosłowiańskim.

Wszyscy informatorzy biorący udział w badaniu to osoby dwu- lub wielojęzyczne, przy czym podstawowym narzędziem ich komunikacji jest język ukraiński. W zależności od sytuacji komunikacyjnej posługują się oni również językiem polskim i rosyjskim. Jednak w zdecydowanej większości przypadków polszczyzna jest używana okazjonalnie: najczęściej podczas odbywających się

${ }_{6}$ W przetranskrybowanych przykładach i fragmentach wypowiedzi K1942 nie wprowadzano rozróżnienia na [1] i [1]. 
w Towarzystwie Kultury Polskiej Ziemi Lwowskiej w Stryju uroczystości, mszy świętej w tamtejszym kościele czy rozmów z polskojęzycznymi krewnymi bądź znajomymi.

Wstępna analiza materiału w postaci nagranych wywiadów pokazuje, że sytuacja językowa mniejszości polskiej w Stryju nie jest jednoznaczna. Wybór kodu uzależniony jest od czynników historyczno-politycznych, socjologicznych i socjolingwistycznych, takich jak na przykład miejsce urodzenia, typ rodziny, otoczenie językowe. Znaczenie mają również postawy wobec języka. Zauważa się, że przedstawiciele pokolenia młodszego i średniego, ze względu na brak możliwości zetknięcia się i wyniesienia polszczyzny z domu rodzinnego, praktycznie w ogóle nie używają języka przodków w codziennych sytuacjach. Z kolei przedstawiciele starszego pokolenia starają się posługiwać językiem polskim w kontaktach ze swoimi dziećmi i wnukami (prowadzenie rozmów, wplatanie polskich słów). Obecnie polszczyzna traktowana jest przez mniejszość polską w Stryju przede wszystkim jako język przodków, język Kościoła oraz język Towarzystwa Kultury Polskiej Ziemi Lwowskiej. O ile w przypadku pierwszego chodzi o posługiwanie się językiem w sytuacjach codziennych, o tyle w pozostałych o miejsce, w którym okazjonalnie dochodzi do przełączenia kodu $\mathrm{z}$ ukraińskiego na polski.

\section{ROZWIAZZANIA SKRÓTÓW}

pol. - polski

por. - porównaj

ukr. - ukraiński

\section{BIBLIOGRAFIA}

Bı๐ONOżKo Eugeniusz, 2013, Obcość języka ojczystego (lingwistyczna identyfikacja Polaków na Ukrainie), „Studia Politologica Ucraino-Polona”, nr 3, s. $100-105$.

BoksZaŃski Zbigniew, Piotrowski Andrzej, ZióŁKowski Marek, 1977, Socjologia języka, Wydawnictwo Wiedza Powszechna, Warszawa.

Chlebowski Bronisław, WALewski Władysław, red., 1890, Słownik geograficzny Królestwa Polskiego i innych krajów słowiańskich, t. XI, Druk „WIEKU” Nowy Świat nr 61, Warszawa.

GŁuszKowski Michał, 2007, Jazykowaja situacija i kulturnoje samosoznanije dietiej i mołodieży Polskowo Kulturnowo Centra im. Kornela Makuszynskowo 
w Stryje, w: A.K. Gadomski, red., Krymsko-polskij sbornik naucznych rabot, t. 5: Dni Adama Mickiewicza w Krymu, Universum, Simferopol', s. 205-212. GŁuszKowski Michał, 2013, Wpływ postawy wobec języka na charakter kontaktu językowego. Na przykładzie sytuacji językowej dzieci i młodzieży z Polskiego Centrum Kulturalnego w Stryju (Ukraina), w: J. Mędelska, E. Titarenko, red., Dialog kultur. Języki wschodniostowiańskie w kontakcie z polszczyzna $i$ innymi językami europejskimi, Wydawnictwo Uniwersytetu Kazimierza Wielkiego, Bydgoszcz, s. 21-32.

GŁuszKowski Michał, 2014, Rola Polskiego Centrum Kulturalnego w ksztattowaniu kompetencji językowej i przyszłych losów tamtejszej młodzieży polskiego pochodzenia, w: W. Dzianisava, P. Juszkiewicz, A. Okuskaite, red., Polskie Kresy Wschodnie i ludzie stamtad. II edycja, Dom Wydawniczy Elipsa, Warszawa, s. 171-177.

GŁuszKowski Michał, 2018, Rural sociology and 'rural' linguistics. The biographical methody in the study of dialects and languages in contact, „Eastern European Countryside", no. 24, s. 43-62.

Grek-Pabisowa Iryda, Maryniakowa Irena, 1997, Język polski na Kresach pólnocno-wschodnich dawniej $i$ dziś, w: I. Grek-Pabisowa, red., Historia $i$ wspótczesność języka polskiego na Kresach wschodnich, Slawistyczny Ośrodek Wydawniczy, Warszawa, s. 27-109.

HandKe Kwiryna, 1997, Polszczyzna pólnocnokresowa na tle terytorialnego i społecznego zróżnicowanie języka polskiego, w: I. Grek-Pabisowa, red., Historia $i$ współczesność języka polskiego na Kresach wschodnich, Slawistyczny Ośrodek Wydawniczy, Warszawa, s. 9-26.

Kostecka-SAdowa Anna, 2008, Stan współczesnej polszczyzny Mościsk i okolic, w: Z. Cygal-Krupa, red., Współczesna polszczyzna: stan, perspektywy, zagrożenia, Państwowa Wyższa Szkoła Zawodowa w Tarnowie, Tarnów, s. $247-257$.

Kostecka-Sadowa Anna, 2017, Sytuacja języka polskiego w obcym otoczeniu językowym. Zarys problematyki (na przykładzie obwodu lwowskiego), „Prace Językoznawcze", nr 19/2, s. 73-86.

KoścIÓŁEK Jakub, 2012, Język ukraiński wobec wyzwań współczesnej sytuacji społeczno-politycznej na Ukrainie, „Przegląd Wschodnioeuropejski”, nr 3, s. 449-456.

Krasowska Helena, 2015, Stan badań nad polszczyzna poludniowokresowa. Przeszłość i perspektywy badawcze, w: I. Bundza, E. Kowalewski, A. Krawczuk, O. Slyvynskij, red., Język polski i polonistyka w Europie Wschodniej: przeszłość i wspótczesność, INKOS, Kijów, s. 55-68. 
Kurzowa Zofia, 1983, Polszczyzna Lwowa i Kresów południowo-wschodnich do 1939 roku, Państwowe Wydawnictwo Naukowe, Warszawa-Kraków.

Kunzowa Zofia, 1993, O mowie Polaków na kresach wschodnich, Wydawnictwo i Drukarnia „Secesja”, Kraków.

Kunzowa Zofia, 1997, Historia i wspótczesność języka polskiego na Kresach południowo-wschodnich, w: I. Grek-Pabisowa, red., Historia i współczesność języka polskiego na Kresach wschodnich, Slawistyczny Ośrodek Wydawniczy, Warszawa, s. 111-165.

LEOŃSKI Jacek, 1993, Różne sposoby ujmowania metody biograficznej w socjologii, w: T. Rzepa, J. Leoński, red., O biografii i metodzie biograficznej, Wydawnictwo Nakom, Poznań, s. 25-32.

MiodunKa Władysław, 2016, Biografia językowa jako jedna z metod badania dwujęzyczności, w: R. Dębski, W. Miodunka, red., Bilingwizm polsko-obcy dziś. Od teorii i metodologii badań do studiów przypadków, Księgarnia Akademicka, Kraków, s. 49-87.

OlszaŃski Tadeusz Andrzej, 2013, Kresy Zachodnie: miejsce Galicji Wschodniej $i$ Wotynia w państwie ukraińskim, „Prace Ośrodka Studiów Wschodnich”, $\mathrm{nr} 43$.

Rieger Janusz, Cechosz Iwona, DzięGiel Ewa, 2002, Język polski na Ukrainie w końcu XX wieku. Cz. I. Stan i status polszczyzny. Gwary polskie w Lwowskiem, na Tarnopolszczyźnie i na Podolu, Wydawnictwo Semper, Warszawa.

Rieger Janusz, Cechosz Iwona, DzięGiel Ewa, 2007, Język polski na Ukrainie w końcu XX wieku. Cz. II. Polszczyzna w Lwowskiem, Żytomierskiem i na Podolu. Teksty, Wydawnictwo Lexis, Kraków.

ZielińsKa Anna, 2013, Mowa pogranicza. Studium o językach i tożsamościach w regionie lubuskim, Instytut Slawistyki Polskiej Akademii Nauk, Warszawa.

ZIELIŃSKA Maria, 2011, Rola polszczyzny w życiu młodych użytkowników języka polskiego na Ukrainie Zachodniej, ,Język, Komunikacja, Informacja”, t. 6, s. $127-134$.

ZIELIŃSKA Maria, 2012, Sytuacje komunikacyjne a umiejętności tworzenia wypowiedzi przez młodych użytkowników języka polskiego na terenach Ukrainy Zachodniej, „SŁOWO. Studia Językoznawcze”, nr 3, s. 192-200. 


\title{
Angelika Pawlaczyk \\ SYTUACJA JĘZYKOWA MNIEJSZOŚCI POLSKIEJ \\ W STRYJU (UKRAINA)
}

\begin{abstract}
Streszczenie
Stryj jest miastem znajdującym się w obwodzie lwowskim, około $75 \mathrm{~km}$ na południe od Lwowa. Z myślą o mieszkającej tam ludności polskiego pochodzenia zajęto się edukacją i krzewieniem wśród niej polskiej kultury, historii i tradycji. Obecnie zajmuje się tym m.in. Towarzystwo Kultury Polskiej Ziemi Lwowskiej. Celem organizacji jest przede wszystkim zrzeszanie mniejszości polskiej, ale również dbanie o zachowanie i propagowanie wśród jej członków polskiej kultury, historii i tradycji. Celem niniejszego artykułu jest omówienie sytuacji językowej wspólnoty polskiej na podstawie trzech wybranych biografii językowych. Materiał językowy stanowią wywiady przeprowadzone z dwu- lub wielojęzycznymi przedstawicielami poszczególnych pokoleń podczas odbywającej się w lipcu 2018 roku ekspedycji dialektologicznej.
\end{abstract}

\section{THE LANGUAGE SITUATION OF THE POLISH MINORITY OF STRIY (UKRAINE)}

\section{Summary}

Striy is a city in the Lviv region around 75 kilometers south of Lviv. Polish culture, history and tradition have spread there through the Polish community living in the area. Currently, the Association of Polish Culture of the Lviv Land is one of the organisations involved in the process. The organisation aims to bring together the Polish minority, but also engage their members in cultivating and propagating Polish culture, history and tradition. The main aim of the present article is to discuss the linguistic situation of the Polish community on the basis of the three chosen linguistic biographies. The linguistic data, gathered in July 2018 during a dialectological expedition, comprises interviews conducted with bilingual or multilingual representatives of particular generations. 